\title{
Sezaryen Sonrası Tromboflaksisinin Uygulanan Olguların Değerlendirilmesi
}

\author{
İsmail Bıyık@
}

Karacabey Devlet Hastanesi, Kadın Hastalıkları ve Doğum, Bursa, Türkiye

İsmail Bıyık, Op. Dr.

İletişim:

Op. Dr. İsmail Biyık

Karacabey Devlet Hastanesi, Kadın Hastalıkları ve Doğum, Bursa, Türkiye

Tel: +905327867031

E-Posta: dribiyik@hotmail.com

Gönderilme Tarihi : 30 Haziran 2019

Revizyon Tarihi : 30 Haziran 2019

Kabul Tarihi : 24 Eylül 2019
ÖZET

Amaç: Karacabey Devlet Hastanesi'nde sezaryen sonrası enoksaparin ile uygulanan tromboprofilaksinin endikasyonları ve etkinliği değerlendirildi.

Hastalar ve yöntem: Karacabey Devlet Hastanesinde 1 0cak 2018-31 Aralık 2018 tarihleri arasında toplam 611 doğum gerçekleştirildi. 328 (\%54) gebe sezaryen ile doğurtuldu. Sezaryen ile doğurtulan gebelerin $22(\% 7)$ 'sine enoksaparin ile 10 gün postpartum tromboflaksi uygulandı. Hastalar postoperatif 11.günde kontrole çağrıldı. Kontrollerinde DVT, pulmoner emboli, ilaç alerjisi, kanama, enjeksiyon yerinde reaksiyon açısından sorgulandı.

Bulgular: Olguların yaş ortalaması 29,68 $\pm 6,02$ yıl olarak hesaplandı. Sezaryen endikasyonları arasında en sık eski sezaryen $9(\% 40,9)$ bulunmaktaydı. Trombofilaksi endikasyonları arasında en sık obezite $12(\% 54,5)$ bulunmaktaydı. $13(\% 59,1)$ lohusaya enoksaparin $60 \mathrm{mg} / \mathrm{gün}, 9(\% 40,9)$ 'una ise enoksaparin $40 \mathrm{mg} /$ gün dozunda trombofilaksi verildi. Olguların hiçbirinde DVT, pulmoner emboli veya enoksaparine bağlı komplikasyon görülmedi.

Sonuç: Bu çalışmada tromboemboli açısından yüksek-orta riske sahip gebelere düşük molekül ağırlıklı heparin ile trombofilaksi verilmesi nin etkin ve güvenli olduğu bulundu.

Anahtar sözcükler: Postpartum trombofilaksi, sezaryen, enoksaparin, derin ven trombozu, pulmoner emboli

\section{EVALUATION OF THROMBOPROPHYLAXIS AFTER CESAREAN SECTION}

\section{ABSTRACT}

Objectives: The indications and the efficacy of enoxaparin-induced thromboprophylaxis after the cesarean section in Karacabey State Hospital were evaluated.

Patients and methods: A total of 611 births were performed between 1 January 2018 and 31 December 2018 In Karacabey State Hospital. Three hundred and twenty-eight (54\%) pregnant women were delivered by cesarean section. Twenty-two (7\%) pregnant women who were delivered by cesarean section underwent enoxaparin and 10 days postpartum thromboprophylaxis. Patients were called for control on the 11th postoperative day. In their control, DVT was questioned in terms of pulmonary embolism, drug allergy, bleeding, injection site reaction.

Results: The mean age of the patients was $29.68 \pm 6.02$ years. The most indication was repeated cesarean section $9(40.9 \%)$. The most common thromboprophylaxis indication was obesity $12(54.5 \%)$. Thirteen (59.1\%) patients were given enoxaparin $60 \mathrm{mg}$ / day and 9 (40.9\%) had enoxaparin (40 mg / day). None of the patients had DVT, pulmonary embolism or enoxaparin-related complications.

Conclusion: In this study, it was found that the administration of low molecular weight heparin and thromboprophylaxis was effective and safe for pregnant women with high-medium risk for thromboembolism.

Keywords: Postpartum thromboprophylaxis, cesarean section, enoxaparin, deep vein thrombosis, pulmonary embolism 
D erin venöz trombozu (DVT) ve pulmoner emboli (PE) gebelikte morbidite ve mortalitesi yüksektir. Gebelikte venöz tromboemboli insidansının 1-2 /1000 olduğu ve mortalitesinin de 1/100.000 olduğu tahmin edilmektedir (1-5). Tromboemboli kaynaklı anne ölümü önlenebilir olması ve oranının görece sabit kalması nedeniyle oldukça önemlidir (6).

Tromboemboli oluşma riski sezaryen doğumda vajinal doğuma kıyasla daha fazladır (7). Yapılan metanalizde sezaryenin postpartum venöz tromboembolizm (VTE) gelişimi açısından bağımsız risk faktörü ve sezaryen sonrası VTE insidansının 3/1000 olduğu bildirilmiştir (7). Venöz tromboemboli riski postpartum dönemde gebelik döneminden daha fazladır (8).

Türkiye'de 2013 yılında pulmoner emboliye bağlı 224 maternal ölüm vakası rapor edilmiştir. Bu kayıpların 17 tanesi pulmoner emboliye bağlı olarakgörülmüş ve PE'ye bağlı ölümlerin maternal mortalitenin \%7.58 ini oluşturduğu bilinmektedir (9). Ülkemizde tromboemboli açııından orta-yüksek riskli olan gebe ve lohusaları önceden belirlemeye yönelik ulusal rehber oluşturulmuştur (10). Ancak postpartum trombofilaksinin etkinliği tartışmalıdır (11). Postpartum trombofilakside değişik ajanlar kullanılmaktadır. En yaygın kullanılan ilaç grubu düşük molekül ağırlıklı heparin (DMAH)'dir. Enoksaparin yaygın olarak kullanılan DMAH'dir.

Bu çalışmada ** hastanesinde sezaryen sonrası enoksaparin ile uygulanan tromboprofilaksinin endikasyonları ve etkinliği değerlendirildi.

\section{Gereç ve Yöntem}

Karacabey Devlet hastanesinde 1 Ocak 2018-31 Aralık 2018 tarihleri arasında toplam 611 doğum gerçekleştirildi. 328 (\%54) gebe sezaryen ile doğurtuldu. Retrospektif kesitsel çalışmamızda yalnızca sezaryen ile doğum yapan gebelerin bilgileri değerlendirildi. Sezaryen ile doğurtulan gebelerin 22 (\%7)'sine enoksaparin ile 10 gün postpartum tromboflaksi uygulandı.

Dışlama kriterleri: heparin yada heparin türevlerine karşı alerjisi olanlar, heparin kaynaklı trombositopeni öyküsü olanlar, karaciğer disfonksiyonu olanlar (Childe Pugh sınıflaması > Grade A), venöz tromboembolizm bulguları olanlar, kanama bulgusu(intraabdominal, retroperitoneal, intrakranial veya diğer vital) olanlar olgulara enoksaparin verilmedi. Karacabey devlet hastanesi ikinci basamak sağlık kuruluşu olması nedeniyle bilinen yüksek riskli trombofilisi, geçirilmiş venöz tromboemboli (VTE) öyküsü, mekanik kalp kapağı olanlar, kanser, kalp yetmezliği, aktif sistemik lupus eritomatozis, aktif inflamatuar barsak hastalığı ve aktif inflamatuar poliartropati gibi inflamatuar hastalıklar, nefrotik sendrom, nefropati, Tip I diyabetes mellitus, orak hücre hastalığı, mevcut intravenöz ilaç bağımlıı̆ı̆ı olanlar sezaryen için üçüncü basamak sağlık kuruluşuna sevk edildi.

Çalışma retrospektif dosya taraması şeklinde olması nedeniyle etik kurul onayı alınmamıştır.

T.C Sağlık Bakanlığı́nın 2017 yılında yayınlamış olduğu 'gebelikte venöz tromboembolizm yönetim rehberi' (12) VTE risk faktörleri tablo 1'de verilmiştir. Tablo 1'de belirtilen risk faktörlerinden $\geq 2$ puan alanlara (geçirilmiş VTE veya yüksek riksli trombofili dışında kalan) postnatal

Tablo 1. Gebelik ve lohusalık döneminde tromboz ve emboli için risk faktörleri

\begin{tabular}{|c|c|}
\hline & Puan \\
\hline \multicolumn{2}{|l|}{ Mevcut olan risk faktörleri } \\
\hline Major cerrahi ile ilgisi olmayan geçirilmiş VTE öyküsü & 4 \\
\hline Major cerrahi sonrası VTE öyküsü & 3 \\
\hline Bilinen yüksek riskli trombofili & 3 \\
\hline $\begin{array}{l}\text { Medikal eşlik eden hastalıklar (kanser, kalp yetmezliği, aktif SLE, } \\
\text { aktif inflamatuar barsak hastalığı ve aktif inflamatuar poliartropati } \\
\text { gibi inflamatuar hastalıklar, nefrotik sendrom, nefropatili Tip I DM, } \\
\text { orak hücre hastalığı, mevcut intravenöz ilaç bağımlılığı) }\end{array}$ & 3 \\
\hline 1.derece akrabada tetiklenmiş ya da östrojen ilişkili VTE & 1 \\
\hline VTE olmaksızın bilinen düşük riskli trombofili varlığı & 1 \\
\hline$>35$ yaş & 1 \\
\hline Obezite; Gebelik başlangıcı vücut kitle indeksi $\geq 30$ kg/m² & 1 \\
\hline Obezite; Gebelik başlangıcı vücut kitle indeksi $\geq 40$ kg/m² & 2 \\
\hline Parite $\geq 3$ & 1 \\
\hline Sigara içiciliği (>10 adet/gün) & 1 \\
\hline Büyük variköz ven varlığı & 1 \\
\hline \multicolumn{2}{|l|}{ Obstetrik risk faktörleri } \\
\hline Mevcut gebelikte preeklampsi varlığı & 1 \\
\hline $\begin{array}{l}\text { Üremeye yardımcı teknolojiler/in vitro fertilizasyon (sadece } \\
\text { antenatal) }\end{array}$ & 1 \\
\hline Çoğul gebelik & 1 \\
\hline Eylemde sezaryen ile doğum & 2 \\
\hline Elektif sezaryen ile doğum & 1 \\
\hline Orta pelvis ya da rotasyonel operatif doğum & 1 \\
\hline Uzamış eylem (>24 saat) & 1 \\
\hline Postpartum kanama (>1 It veya transfüzyon ihtiyacı) & 1 \\
\hline Mevcut gebelikte preterm doğum $\left(<37^{+0}\right.$ hafta $)$ & 1 \\
\hline Mevcut gebelikte ölü doğum & 1 \\
\hline \multicolumn{2}{|l|}{ Geçici risk faktörleri } \\
\hline $\begin{array}{l}\text { Gebelikte veya lohusalıkta epizyotomi hariç herhangi bir cerrahi } \\
\text { müdahale (örn, appendektomi, postpartum sterilizasyon) }\end{array}$ & 3 \\
\hline Hiperemezis gravidarum & 3 \\
\hline Ovaryan hiperstimülasyon sendromu (sadece 1.trimester) & 4 \\
\hline Mevcut sistemik enfeksiyon & 1 \\
\hline İmmobilazsyon ( $\geq 3$ gün), dehidratasyon & 1 \\
\hline Uzun mesafeli yolculuk (>4 saat) & 1 \\
\hline
\end{tabular}


Tablo 2. Sezaryen sonrası trombofilaksi uygulanan kadınların verileri

\begin{tabular}{|c|c|c|c|c|c|c|c|c|c|c|}
\hline Ay & Hasta yaşı & G & $P$ & GH & Endikasyon & Bebek tartısı & Anestezi şekli & $\begin{array}{l}\text { Tromboprofilaksi } \\
\text { endikasyonu }\end{array}$ & Ağırlık (kg) & $\begin{array}{c}\text { Trombo- profilaksi } \\
\text { şekli }\end{array}$ \\
\hline Ocak & 39 & 6 & 3 & 37 & Eski CS & $3100 \mathrm{~g}$ & genel & $\begin{array}{c}\text { Transfüzyon (2 ü es) } \\
35 \text { yaş üstü }\end{array}$ & 70 & $\begin{array}{l}\text { Enoksaparin } \\
40 \text { mg/gün }\end{array}$ \\
\hline Ocak & 31 & 1 & 1 & 39 & $\begin{array}{l}\text { Primigravid makat } \\
\text { geliş }\end{array}$ & $2900 \mathrm{~g}$ & spinal & $\begin{array}{c}\text { BMl: } 40,4 \text { kg/m² } \\
1+\text { proteinüri }\end{array}$ & 97 & $\begin{array}{l}\text { Enoksaparin } \\
60 \text { mg/gün }\end{array}$ \\
\hline Ocak & 28 & 2 & 2 & 40 & Fetal distress & $3200 \mathrm{~g}$ & genel & $\begin{array}{l}\text { Transfüzyon (2 ü es) } \\
\text { Eylemde sezaryen }\end{array}$ & 68 & $\begin{array}{l}\text { Enoksaparin } \\
40 \mathrm{mg} / \mathrm{gün}\end{array}$ \\
\hline Ocak & 22 & 1 & 1 & 40 & Fetal makrozomi & $4600 \mathrm{~g}$ & genel & BMI: 38,64 kg/m² & 117 & $\begin{array}{l}\text { Enoksaparin } \\
60 \text { mg/gün }\end{array}$ \\
\hline Şubat & 26 & 2 & 2 & 39 & Eski CS & $4000 \mathrm{~g}$ & genel & BMI: 41,15 kg/m² & 108 & $\begin{array}{l}\text { Enoksaparin } \\
60 \text { mg/gün }\end{array}$ \\
\hline Şubat & 31 & 3 & 3 & 39 & Mükerrer CS & $3600 \mathrm{~g}$ & genel & $\begin{array}{c}\text { BMI: } 36,33 \mathrm{~kg} / \mathrm{m}^{2} \\
\text { Kronik HT } \\
\text { Sigara }(+)\end{array}$ & 105 & $\begin{array}{l}\text { Enoksaparin } \\
60 \text { mg/gün }\end{array}$ \\
\hline Mart & 26 & 1 & 1 & 40 & İlerlemeyen travay & $3900 \mathrm{~g}$ & genel & $\begin{array}{l}\text { Başarısız vakum } \\
\text { denemesi }\end{array}$ & 80 & $\begin{array}{l}\text { Enoksaparin } \\
40 \mathrm{mg} / \mathrm{gün}\end{array}$ \\
\hline Mart & 32 & 3 & 3 & 39 & Mükerrer CS & $2800 \mathrm{~g}$ & genel & Transfüzyon (2 ü es) & 75 & $\begin{array}{l}\text { Enoksaparin } \\
40 \text { mg/gün }\end{array}$ \\
\hline Mart & 37 & 3 & 3 & 40 & Fetal makrozomi & $4000 \mathrm{~g}$ & genel & BMI: 43,75 kg/m² & 112 & $\begin{array}{l}\text { Enoksaparin } \\
60 \text { mg/gün }\end{array}$ \\
\hline Nisan & 24 & 2 & 2 & 40 & Fetal makrozomi & $4200 \mathrm{~g}$ & genel & $\begin{array}{l}\text { Transfüzyon (2 ü es) } \\
\text { BMl: 35,89 kg/m² }\end{array}$ & 84 & $\begin{array}{l}\text { Enoksaparin } \\
40 \text { mg/gün }\end{array}$ \\
\hline Nisan & 29 & 4 & 2 & 40 & Fetal makrozomi & $3900 \mathrm{~g}$ & spinal & $\begin{array}{l}\text { Trombofili öyküsü } \\
\text { (Faktör V leiden } \\
\text { heterozigot) } \\
\text { BMl: } 36,74 \mathrm{~kg} / \mathrm{m}^{2}\end{array}$ & 115 & $\begin{array}{l}\text { Enoksaparin } \\
60 \text { mg/gün }\end{array}$ \\
\hline Nisan & 36 & 3 & 3 & 39 & Eski CS & $3600 \mathrm{~g}$ & genel & BMI: 44,5 kg/m² & 114 & $\begin{array}{l}\text { Enoksaparin } \\
60 \text { mg/gün }\end{array}$ \\
\hline Mayıs & 21 & 2 & 2 & 39 & Eski CS & $2880 \mathrm{~g}$ & genel & BMI: 40 kg/m² & 109 & $\begin{array}{l}\text { Enoksaparin } \\
60 \text { mg/gün }\end{array}$ \\
\hline Temmuz & 41 & 2 & 2 & 39 & Eski CS & 3900 & spinal & BMI: 37,6 kg/m² & 105 & $\begin{array}{l}\text { Enoksaparin } \\
60 \text { mg/gün }\end{array}$ \\
\hline Temmuz & 23 & 4 & 2 & 39 & Fetal makrozomi & $4080 \mathrm{~g}$ & spinal & BMl: 41,8 kg/m² & 118 & $\begin{array}{l}\text { Enoksaparin } \\
60 \text { mg/gün }\end{array}$ \\
\hline Temmuz & 27 & 3 & 3 & 39 & Mükerrer CS & $2500 \mathrm{~g}$ & genel & BMI: 39,1 kg/m² & 100 & $\begin{array}{l}\text { Enoksaparin } \\
60 \text { mg/gün }\end{array}$ \\
\hline Temmuz & 39 & 3 & 2 & 39 & Eski CS & $3500 \mathrm{~g}$ & genel & $\begin{array}{l}\text { Gestasyonel HT } \\
35 \text { yaş üstü }\end{array}$ & 78 & $\begin{array}{l}\text { Enoksaparin } \\
40 \text { mg/gün }\end{array}$ \\
\hline Temmuz & 28 & 2 & 2 & 39 & Eski CS & $3100 \mathrm{~g}$ & spinal & Ağır preeklampsi & 103 & $\begin{array}{l}\text { Enoksaparin } \\
60 \text { mg/gün IU }\end{array}$ \\
\hline Eylül & 24 & 2 & 2 & 41 & Fetal distress & $3950 \mathrm{~g}$ & genel & $\begin{array}{l}\text { Transfüzyon (3 ü es) } \\
\text { Preop Hb: 7,4 g/dL }\end{array}$ & 85 & $\begin{array}{l}\text { Enoksaparin } \\
40 \text { mg/gün }\end{array}$ \\
\hline Ekim & 35 & 2 & 2 & 39 & Eski CS & $4200 \mathrm{~g}$ & spinal & BMI: 37,2 kg/m² & 105 & $\begin{array}{l}\text { Enoksaparin } \\
60 \text { mg/gün }\end{array}$ \\
\hline Aralık & 23 & 1 & 1 & 41 & Fetal distress & $2800 \mathrm{~g}$ & genel & Preeklampsi & 74 & $\begin{array}{l}\text { Enoksaparin } \\
40 \text { mg/gün }\end{array}$ \\
\hline Aralık & 31 & 4 & 3 & 37 & Eski CS & $3000 \mathrm{~g}$ & genel & $\begin{array}{l}\text { Trombofili öyküsü } \\
\text { Atoni (B-Lynch sütür) }\end{array}$ & 71 & $\begin{array}{l}\text { Enoksaparin } \\
40 \text { mg/gün }\end{array}$ \\
\hline
\end{tabular}




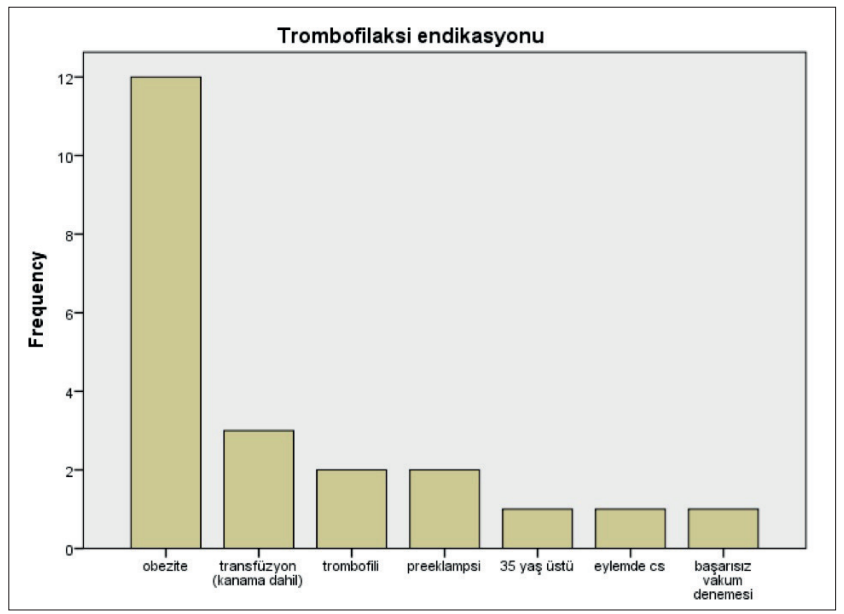

Şekil 1. Olguların trombofilaksi endikasyonları

dönemde 10 gün süre ile profilaktik enoksaparin uygulandı. Akut fetal distress, kordon prolapsusu, dekolman plasenta gibi çok acil olan durumlar hariç tüm olgulara sezaryen öncesi mekanik tromboproflaksi (varis çorabı) uygulandı. Enoksaparin için doz ayarlaması maternal kiloya göre yapıldı. 50 kilonun altındakilere 20 mg/gün, 5090 arasındakilere $40 \mathrm{mg} /$ gün, 90-130 kg arasındakilere 60 $\mathrm{mg} / \mathrm{gün}$ dozunda tek doz halinde verildi. Trombofilaksiye postoperatif 12. saatte başlandı. Hastalar postoperatif en geç 5 saat sonra mobilize edildi. Mobilize olma sürecinden önce yatakta hastaların hareket etmeleri sağlandı. Hastalar postoperatif 24-48 saat sonra taburcu edildi. Hastalar postoperatif 11.günde kontrole çağrıldı. Kontrollerinde DVT, pulmoner emboli, ilaç alerjisi, kanama, enjeksiyon yerinde reaksiyon açısından sorgulandı. Tedavi dozunda enoksaparin alması gereken hastamız olmadığı için yalnızca profilaksi alan hastaların verileri analiz edildi

\section{Sonuçlar}

Olguların yaş ortalaması $29,68 \pm 6,02$ yıl olarak hesaplandı. Gravida 2 (1-6), Parite 2 (1-3) olarak bulundu. Bebek ağırlığı $3532,27 \pm 581,06 \mathrm{~g}$ olarak ölçüldü. Maternal ağırlık doğum esnasında 95,14 $\pm 17,35 \mathrm{~g}$ olarak ölçüldü. Aylara göre bakıldığında en çok temmuz ayında $5(\% 22,7)$ lohusaya enoksaparin ile trombofilaksi uygulandığı görüldü. Sezaryen endikasyonları arasında en sık eski sezaryen $9(\% 40,9)$ bulunmaktaydı. $16(\% 72,2)$ olguya genel, $6(\% 27,3)$ olguya spinal anestezi uygulandı. Trombofilaksi endikasyonları arasında en sık obezite $12(\% 54,5)$ bulunmaktaydı. $13(\% 59,1)$ lohusaya enoksaparin $60 \mathrm{mg} /$ gün, $9(\% 40,9)^{\prime}$ 'una ise enoksaparin $40 \mathrm{mg} / \mathrm{gün}$ dozunda trombofilaksi verildi. Olguların demografik, doğum ve profilaksi verileri tablo 2'de verilmiştir. Olguların hiçbirinde DVT, pulmoner emboli veya enoksaparine bağı komplikasyon görülmedi.

\section{Tartışma}

Profilaksi açısından değerlendirmek için gebelik ve lohusalık döneminde tromboemboli için orta-yüksek riskli olan kadınları belirlemek gereklidir. Tüm dünyada ortak olarak kullanılan, genel kabul gören kılavuz bulunmamaktadır. Bunun yerine bazı dernekler ve ülkeler kendi kılavuzlarını oluşturmuştur (13-16). Ülkemizde RCOG kılavuzunu esas alan ulusal kılavuz kullanılmaktadır (12).

Elektif sezaryen sonrası VTE insidansı $0.63 / 1000$, acil sezaryen sonrası VTE insidansı ise $0.84 / 1000$ olarak bildirilmiştir (17). Postpartum trombofilaksinin etkinliğini gösteren çalışmalar mevcuttur (18). Uluslar arası kılavuzların derlemesinde postpartum 1 hafta LMWH verilmesinin VTE gelişme intimalini \%70 azalttığı belirtilmiştir (11). Ancak yapılan metaanalizlerde, literatürdeki çalışmaların kanıt düzeyinin düşük olduğuna dikkat çekilmiştir. Kılavuzların çoğunun olgu-kontrol çalışmalarından yola çıkılarak oluşturulduğu vurgulanmıştır. Sultan et al. pospartum VTE insidansını 637/100.000 insan-yılı olarak hesaplamışlardır (19). Bu insidans esas alınarak hesap yapıldığında 1 VTE'yi önlemek için 4000 kadının tedavi edilmesi gerekmektedir.

LMWH'in kanama, hematom gibi yan etkileri olabilir (20). Heparininin neden olduğu trombositopeni, osteoporoz nadir görülen yan etkilerdir (21). Yapılan gözlemsel çalışmalarda LMWH kullanımına bağlı ciddi kanama intimali \%0.3-1.1 olarak bildirilmiştir (22-24). Her bir VTE'yi önlemek için LMWH ile tedavinin, 2 major kanama, 7 yara hematomu ve 6 transfüzyon vakasına neden olacağı hesaplanmıştır (11).

Dünya Sağlık Örgütü gelişmiş ülkelerde pulmoner emboliye bağlı maternal mortalite oranını $\% 14.9$ olarak verirken (25), pulmoner emboli İngiltere'de tromboemboliye bağlı maternal mortalitenin \%31.1 ini (26), Amerika'da hastalık kontrol merkezi (CDC) verilerine göre de \%9.3 ini oluşturmaktadır (27). Türkiye'de ise tromproboflaksi yapılmadan PE'ye bağlı maternal mortalite \%7.58 olarak bulunmuştur (9). Dolayısı ile ülkemizde DVT ve PE'ye bağlı maternal ölüm oranları, ulusal kılavuz hazırlanırken esas alınan RCOG'un kullanıldığı İngiltere'ye göre daha azdır. Bu nedenle risk faktörlerini ve sezaryen sonrası postpartum trombofilaksi hedeflerini belirlerken DVT ve PE'nin ülkemizdeki insidansının göz önünde bulundurulması faydalı olabilir.

T.C Sağlık Bakanlığı sezaryen ile doğum yapan gebelerin en az \%50'sine postpartum trombofilaksi uygulanmasını 
hedeflemektedir. Bu çalışmamızda çok acil olarak ameliyata alınan vakalar hariç tüm sezaryen olgularımıza varis çorabı ile mekanik trombofilaksi uygulandı. Olguların 22 (\%7)'sine enoksaparin ile sezaryen sonrası tromboflaksi uygulandı. Olguların hiçbirinde DVT, PE ya da kanama, hematom gibi komplikasyonlar gelişmedi. Olgu sayımızın az olması nedeniyle genelleme yapmaktan ve öneride bulunmaktan kaçınıyoruz. Bununla birlikte risk faktörü

\section{Kaynaklar}

1. Andersen BS, Steffensen FH, Sorensen HT, Nielsen GL, Olsen J. The cumulative incidence of venous thromboembolism during pregnancy and puerperium-an 11 year Danish populationbased study of 63,300 pregnancies. Acta Obstet Gynecol Scand. 1998;77:170-3.

2. Heit JA, Kobbervig CE, James AH, Petterson TM, Bailey KR, Melton $\mathrm{LJ}, 3 \mathrm{rd}$. Trends in the incidence of venous thromboembolism during pregnancy or postpartum: a 30-year population-based study. Ann Intern Med. 2005;143:697-706. [CrossRef]

3. Jacobsen AF, Skjeldestad FE, Sandset PM. Incidence and risk patterns of venous thromboembolism in pregnancy and puerperium-a registerbased case-control study. Am J Obstet Gynecol. 2008;198:233 e1-7. [CrossRef]

4. LiuS, Rouleau J,JosephKS, etal.Epidemiology of pregnancyassociated venous thromboembolism: a population-based study in Canada. $J$ Obstet Gynaecol Can. 2009;31:611-20. [CrossRef]

5. Pomp ER, Lenselink AM, Rosendaal FR, Doggen CJ. Pregnancy, the postpartum period and prothrombotic defects: risk of venous thrombosis in the MEGA study. J Thromb Haemost. 2008;6:632-7. [CrossRef]

6. 1990 DPT Projeksiyonu,1998Hastane Araştırması Projeksiyonu ,2005 UAÖÇ, 2008-2014 SB verileri

7. Blondon M, Casini A, Hoppe KK, Boehlen F, Righini M, Smith NL. Risks of venous thromboembolism after cesarean sections: a metaanalysis. Chest 2016;150:572-96. [CrossRef]

8. Heit JA, Kobbervig CE, James AH, Petterson TM, Bailey KR, Melton LJ III. Trends in the incidence of venous thromboembolism during pregnancy or postpartum: a 30- year population-based study. Ann Intern Med 2005;143: 697-706. [CrossRef]

9. Sanisoğlu S, Uygur D, Keskinkılıç B, Engin-Üstün $Y$, Keskin HL, Karaahmetoğlu S, Özcan A, Esen M, Ongun V, Özkan S. Maternal mortality cases from pulmonary embolism: A nation-wide study in Turkey. J Obstet Gynaecol. 2017;37:151-6. [CrossRef]

10. T.C Sağlık Bakanlığı Türkiye Halk Sağlığı Kurumu. Riskli Gebelikler Yönetim Rehberi. 2014, Ankara.

11. Kotaska A. Postpartum venous thromboembolism prophylaxis may cause more harm than benefit: a critical analysis of international guidelines through an evidence-based lens. BJOG. 2018;125:110916. [CrossRef]

12. T.C Sağlık Bakanlığı Türkiye Halk Sağlığı Kurumu. Gebelikte venöz tromboembolizm yönetim rehberi. 2017, Ankara.

13. ACOG Practice Bulletin No. 196: Thromboembolism in Pregnancy. Obstet Gynecol. 2018;132:e1-e17. [CrossRef]

14. Royal College of Obstetricians and Gynaecologists Green-Top Guideline No. 37a: Reducing the Risk of Thrombosis and Embolism During Pregnancy and the Puerperium. London: RCOG, 2015. bulunan olgularda erken mobilizasyon, varis çorabı ile pnömotik kompresyon ve enoksaparin ile trombofilaksinin etkin ve güvenilir olduğunu düşünüyoruz.

Sonuç olarak; bu çalışmada tromboemboli açısından yüksek-orta riske sahip gebelere düşük molekül ağırlıklı heparin ile trombofilaksi verilmesi nin etkin ve güvenli olduğu bulundu.

15. Sénat MV, Sentilhes $L$, Battut A, et al. Postpartum practice: guidelines for clinical practice from the French College of Gynaecologists and Obstetricians (CNGOF). Eur J Obstet Gynecol Reprod Biol. 2016;202:1-8. [CrossRef]

16. Lindqvist PG, Hellgren M. Obstetric thromboprophylaxis: the Swedish guidelines. Adv Hematol. 2011;2011:157483. [CrossRef]

17. Landon $M B$, Hauth $J C$, Leveno $K$, et al. Maternal and perinatal outcomes associated with a trial ofnlabor after prior cesarean delivery. N Engl J Med 2004;351:2581-9. [CrossRef]

18. Goto M, Yoshizato T, Tatsumura M, Takashima T, Ogawa M, Nakahara $\mathrm{H}$, Satoh S, Sanui A, Eguchi F, Miyamoto S. Safety and efficacy of thromboprophylaxis using enoxaparin sodium after cesarean section: A multi-center study in Japan. Taiwan J Obstet Gynecol. 2015;54:248-52. [CrossRef]

19. Sultan AA, West J, Tata LJ, et al. Risk of first venous thromboembolism in and around pregnancy: a population-based cohort study. $\mathrm{Br} J$ Haematol 2012;156:366-73. [CrossRef]

20. Schulman S, Beyth RJ, Kearon C, Levine MN; American College of Chest Physicians. Hemorrhagic complications of anticoagulant and thrombolytic treatment: American College of Chest Physicians Evidence-Based Clinical Practice Guidelines (8th Edition). Chest 2008;133: 257S-98S. [CrossRef]

21. Sagaram D, Siddiq $Z$, Eisenberger $A B$, et al. Heparin-Induced Thrombocytopenia during Obstetric Hospital Admissions. Am J Perinatol. 2018;35:898-903. [CrossRef]

22. Rodger M. Pregnancy and venous thromboembolism: 'TIPPS' for risk stratification. Hematology Am. Soc. Hematol. Educ. Program 2014;2014:387-92. [CrossRef]

23. Greer IA, Nelson-Piercy C. Low-molecular weight heparins for thromboprophylaxis and treatment of venous thromboembolism in pregnancy: a systematic review of safety and efficacy. Blood 2005;106:401-7. [CrossRef]

24. Bauersachs RM, Dudenhausen J, Faridi A, et al. Risk stratification and heparinprophylaxis to prevent venous thromboembolism in pregnant women. Thromb Haemost 2007;98:1237-45. [CrossRef]

25. Khan KS, Wojdyla D, Say L, Gulmezoglu AM, Van Look PF. WHO analysis of causes of maternal death: a systematic review. Lancet 2006;367:1066-74. [CrossRef]

26. Cantwell R, Clutton-Brock T, Cooper G, et al. Saving mothers' lives: reviewing maternal deaths to make motherhood safer: 2006-2008. The Eighth Report of the Confidential Enquiries into Maternal Deaths in the United Kingdom. BJOG 2011;118(suppl 1):1-203. [CrossRef]

27. Creanga AA, Berg CJ, Syverson C, Seed K, Bruce FC, Callaghan WM. Pregnancy-related mortality in the UnitedStates, 2006-2010. Obstet Gynecol 2015;125:5-12. [CrossRef] 